\title{
Optimization of Desulphurization Process using Lance Injection in Molten Iron
}

\author{
Wenjun MA, ${ }^{1) *}$ Haibo $\mathrm{LI}^{1)}$ Yang CUI, ${ }^{1)}$ Bin CHEN, ${ }^{1)}$ Guoliang LIU ${ }^{1)}$ and Jianli $\mathrm{JI}^{21}$ \\ 1) Shougang Research Institute of Technology, Room 1107, Shougang Research Institute of Technology, No.69, Yangzhuang \\ Road, Shijingshan District, Beijing, 100043 China. \\ 2) Shougang Qian'an Iron \& Steel Co., Ltd, Room 606, Yang DianZi Town Riverside Village, Qian'an, 064404 China.
}

(Received on April 11, 2016; accepted on October 5, 2016; J-STAGE Advance published date: January $26,2017)$

\begin{abstract}
A kinetic model of the $60 \% \mathrm{Mg}$ and $40 \% \mathrm{CaO}$ injection desulphurization was established. The simulation results from the model were verified by sampling, and it was in accord with the sampling results. By analyzing the model, the desulfurization process of high sulfur molten iron had three stages, incubation stage, rapid desulfurization stage and slow desulfurization stage. In order to improve the dynamic conditions and the utilization rate of the desulfurization agent, for the molten iron of sulfur content $\geq 0.035 \%$, a new injection desurphurization mode was developed and applied. The smaller injection rate of powder and the larger flow rate of nitrogen were used in the slow desulfurization stage. Compared with the conventional process, the consumption of the desulfurizing agent is reduced by $10-20 \%$ by using the two-stage injection method.
\end{abstract}

KEY WORDS: injection desulphurization; kinetic model; two-stage injection method; utilization rate.

\section{Introduction}

In recent years, in order to improve the profit of the products and expand the market competitiveness of products, the research on the high efficiency and low cost production technology of the low sulfur and ultra-low sulfur steel has become a focus. It has been proved that the hot metal pretreatment desulfurization technology is currently the most economical and efficient measure of desulphurization. The proportion of hot metal desulphurization is close to $100 \%$ in the some steel plant.

The injection method and the Kanbara Reactor (KR) method are the most extensive and most representative hot metal desulphurization technology.

In Japan, Kanbara et al. ${ }^{1)}$ succeeded in performing sulfur removal to $<30 \mathrm{ppm}$ by the KR method. The KR method using mechanical stirring can provide a good dynamic condition for desulfurization, and the desulfurization agent the lime system. ${ }^{2-5)}$ The sulfur content can be controlled under 10 ppm by the KR method in the some steel plants.

For the deep desulfurization (sulfur content $\leq 30 \mathrm{ppm}$ after desulfurization) hot metal using the injection method, the desulfurization agent generally used the magnesium system with good reaction kinetics and thermodynamics. ${ }^{6-9)}$ A wide variety of materials including $\mathrm{Na}_{2} \mathrm{CO}_{3}, \mathrm{CaO}, \mathrm{CaC}_{2}$ and $\mathrm{Mg}$ have been used to desulphurise iron, but to facilitate desulphurization efficiency and satisfy environmental requirements; nowadays many steel works employ magne-

\footnotetext{
* Corresponding author: E-mail: mawenjun2929@163.com DOI: http://dx.doi.org/10.2355/isijinternational.ISIJINT-2016-167
}

sium alone or in combination with various alkaline metal oxides as the primary desulphurisation agents. ${ }^{10)}$ By using the injection method, the sulfur content can be controlled at $30-50 \mathrm{ppm}$.

For the injection desulphurization method, favorable dynamic conditions are necessary. In order to get a higher desulfurization efficiency, these parameters, the gas flow rate, the rate and depth of injection, the geometry and location of the submerged lance, were studied. ${ }^{11-13)}$

In a steel plant in China, hot metal is desulphurised in the $210 \mathrm{t}$ transfer ladle by injection of $60 \% \mathrm{Mg}$ and $40 \%$ $\mathrm{CaO}$ using nitrogen as a carrier gas. With the adjustment of product structure, the proportion of the deep desulfurization hot metal increased to more than $95 \%$. Some problems, the high consumption of desulfurizer, the large amount of slag, and the unstable resulphurization, are also gradually revealed. It seriously impacted on the normal production and the cost control.

In this work, the process of injection desulphurization was investigated by a kinetic model. The changes of sulfur content were analyzed. The result from the model was verified by sampling. According to the result, a new injection desurphurization mode was developed and applied.

\section{Mathematical Modelling}

Seshadri et $a l .{ }^{13)}$ established the mathematical model of the lime and top slag, but it is not taken into account the magnesium desulphurization. The kinetic model has been proposed based on the following assumptions and considerations: (1) particles of the $\mathrm{CaO}$ and $\mathrm{Mg}$ are spherical; (2) 
the desulfurizing agent does not contain any sulfur; (3) the rate of injection and the temperature and melt weight remain constant; (4) the amount and composition of the top slag are time-dependent and are determined by the carry-over slag and the rate of injection; (5) the fraction of particles entrapped in the melt and those accommodated at the bubble-metal interface remain constant; (6) the mean diameter of the bubbles is a function only of the metal density; (7).

The total rate of desulfurization can be written as the sum of the contributions of the top slag and $\mathrm{CaO}$ and $\mathrm{Mg}$, as given by the equation:

$$
v_{\text {total }}=v_{C a O}+v_{M g}+v_{t o p}
$$

\subsection{Desulphurisation Rate of Top Slag}

The restriction factor of top slag desulphurisation was the sulfur diffusion in the top slag. The mass transfer equation of top slag desulphurisation can be expressed as:

$$
J_{[S]}=L_{S} \cdot K_{s} \cdot\left(C_{[S]}-\frac{C_{(S)}}{L_{S}}\right)
$$

The molar volume concentration is converted into the mass fraction, and the effect of the mix time on the desulphurisation rate was considered. The rate of top slag desulphurisation can be expressed as: ${ }^{14)}$

$$
-\frac{d[\% S]}{d t}=\frac{A_{t o p} \cdot \rho_{Z}}{W_{m}} \cdot K_{s} \cdot L_{S} \cdot\left\{[\% S] \exp \left(-t_{\text {mix }} / t\right)-\frac{(\% S)}{L_{S}}\right\}
$$

The sulfur content of top slag can be expressed as:

$$
(\% S)=\frac{(\% S)_{\mathrm{o}} \cdot W_{s o}+\left\{[\% S]_{o}-[\% S] \exp \left(-t_{\text {mix }} / t\right)\right\} \cdot W_{\mathrm{s}}}{W_{s o}+I_{p} \cdot t \cdot \eta} \ldots
$$

\subsection{Desulphurisation Rate of $\mathbf{C a O}$}

The desulfurization behavior of $\mathrm{CaO}$ has been investigated, ${ }^{12,14,15)}$ and the restriction factor of desulphurisation was the sulfur diffusion in the boundary layer of hot metal. The mass transfer equation of the process can be expressed as:

$$
\mathrm{J}_{[S]}=K_{m} \cdot\left(C_{[S]}-C_{S}^{e}\right)
$$

The molar volume concentration is converted into the mass fraction:

$$
-\frac{d[\% S]}{d t}=\frac{A_{1}}{V_{m}} \cdot K_{m} \cdot\left([\% S]-[\% S]_{e}\right)
$$

where $A_{1}$ is the total contact surface area of particles and the hot metal, and it can be calculated. ${ }^{15)}$ The effect of the mix time on the desulphurisation rate was considered. The rate of top slag desulphurisation can be expressed as: ${ }^{14,15)}$

$$
\begin{aligned}
-\frac{d[\% S]}{d t}= & \frac{6 \cdot \beta \cdot I_{p} \cdot \varphi_{1} \cdot \tau_{p} \cdot \rho_{m}}{d_{s} \cdot W_{m} \cdot \rho_{s}} \cdot K_{m} . \\
& \left\{[\% S] \cdot \exp \left(-t_{m i x} / t\right)-[\% S]_{e}\right\}
\end{aligned}
$$

\subsection{Desulphurisation Rate of $\mathbf{M g}$}

Magnesium existed in two forms at the molten iron temperature. A part of magnesium formed bubbles and react with the sulfur in the molten iron. The other part was dis- solved in molten iron and react with the sulfur in molten iron. Irons et al.'s ${ }^{16)}$ report showed that the proportion of bubbles and the dissolved magnesium was 1:9.

During the desulfurization process of magnesium bubbles, the restriction factor was the sulfur diffusion to the bubble surface in the boundary layer. The mass transfer equation of the process can be expressed as:

$$
J_{[S]}=K_{b} \cdot\left(C_{[S]}-C_{[S]}^{b}\right)
$$

The molar volume concentration is converted into the mass fraction, and the effect of the mix time on the desulphurisation rate was considered. The rate of the desulphurisation of magnesium bubbles can be expressed as: ${ }^{17}$

$$
-\frac{d[\% S]}{d t}=K_{b} \cdot A_{b} \cdot\left\{[\% S] \cdot \exp \left(-t_{\text {mix }} / t\right)-[\% S]_{b}\right\} \ldots
$$

where $A_{b}$ is the specific surface area of the gas-liquid interface, and it can be expressed as:

$$
A_{b}=\frac{6 \cdot Q \cdot \tau_{R T} \cdot \rho_{m}}{W_{m} \cdot d_{b}}
$$

During the desulfurization process of dissolved magnesium, at the initial stage, the restriction factor was the diffusion of the dissolved magnesium at the solid-liquid interface. At the later stage, the restriction factor was the diffusion of the sulfur at the solid-liquid interface. The rate of the desulphurisation of magnesium bubbles can be expressed as: ${ }^{17)}$

$$
\begin{gathered}
-\frac{d[\% S]}{d t}=0.4167 \cdot k \cdot \rho_{m} \cdot[\% S] \exp \left(-t_{\text {mix }} / t\right) . \\
{[\% M g] \exp \left(-t_{\text {mix }} / t\right)}
\end{gathered}
$$

Based on the material balance, the dissolution rate of magnesium can be expressed as:

$$
\begin{array}{r}
\frac{d[\% M g]}{d t}=\frac{100 \cdot B_{1} \cdot \varphi_{2} \cdot I_{p}}{W_{m}}-0.75 \cdot\left\{0.4167 \cdot k \cdot \rho_{m} .\right. \\
{[\% S] \exp \left(-t_{\text {mix }} / t\right) \cdot[\% M g] \exp \left(-t_{\text {mix }} / t\right)}
\end{array}
$$

\subsection{Mathematical Equations}

According to the above analysis, the total rate of desulfurization can be expressed as:

$$
\begin{aligned}
& V_{m}=-\frac{d[\% S]}{d t}=\frac{A \cdot \rho_{Z}}{W_{m}} \cdot K_{s} \cdot L_{s} \cdot\left\{[\% S] \exp \left(-t_{\text {mix }} / t\right)-\frac{(\% S)}{L_{s}}\right\}+ \\
& \frac{6 \cdot \beta \cdot I_{p} \cdot \varphi_{1} \cdot \tau_{p} \cdot \rho_{m}}{d_{s} \cdot W_{m} \cdot \rho_{s}} \cdot K_{m} \cdot\left\{[\% S] \cdot \exp \left(-t_{\text {mix }} / t\right)-[\% S]_{e}\right\}+ \\
& \frac{6 \cdot Q \cdot \tau_{R T} \cdot \rho_{m}}{W_{m} \cdot d_{b}} \cdot K_{b} \cdot\left\{[\% S] \cdot \exp \left(-t_{\text {mix }} / t\right)-[\% S]_{b}\right\}+ \\
& 0.4167 \cdot k \cdot \rho_{m} \cdot[\% S] \exp \left(-t_{\text {mix }} / t\right) \cdot[\% M g] \exp \left(-t_{\text {mix }} / t\right)
\end{aligned}
$$

Equations (4), (12) and (13) formed a closed set of equations. Seshadri et al. ${ }^{13)}$ reported that the calculation process of the sulfur mass transfer coefficient $\left(K_{s}, K_{m}, K_{b}\right)$, and the sulfur partition coefficient $\left(L_{S}\right)$, the average residence time of particles and bubbles $\left(\tau_{p}, \tau_{R T}\right)$, were described in detail. Wang et al. ${ }^{17,18)}$ studied the function equation of the powder penetration ratio $(\beta)$ and the mixing time $\left(t_{m i x}\right)$ by the water 
model experiment.

\section{Results and Discussion}

To solve the above differential equation of first order, first of all, the unknown parameters, $K_{s}, K_{m}, K_{b}, L_{s}, \tau_{p}, \tau_{R T}, \beta$, $t_{\text {mix }}$ were calculated. ${ }^{13,17,18)}$ In addition, characteristics of the desulphurization reagent, carrier gas, liquid iron, top slag, lance and ladle car were presented in Table 1.

The gas flow rate of injecting, the injection rate of powder, and other parameters were set according to the prototype. In addition, the initial sulfur content of the slag was sampled and analyzed. The other process parameters can be obtained according to the above. The initial sulfur content of the hot metal and the total injection time were the initial conditions of the model.

The mathematical model was calculated by using the MATLAB program, with an algorithm based on an explicit Runge-Kutta (4) formula. The instantaneous concentration of sulfur in the hot metal in the desulfurization process was obtained. Moreover, the change trends of the sulfur content at different initial conditions can be obtained.

\subsection{Change of the Sulfur Content}

In the steel plant, the sulfur content in molten iron ranged $0.022 \%$ to $0.065 \%$ and the average was $0.035 \%$. In order to analyze the sulfur change of the different initial content, the initial sulfur content was set to $0.03 \%$ and $0.06 \%$. To verify the accuracy of the simulated results, the samples were taken from the hot metal in the different desulfurization time. The compositions of samples were analyzed by ICP-AES and shown in Table 2.

Figure 1 showed the simulated and measured results. It can be seen the simulation results were in accordance with the sampling results. The change trends of the sulfur content were shown. But it can be seen that the change trends of $0.06 \%$ sulfur and $0.03 \%$ sulfur were different. During the first $120 \mathrm{~s}$ (seconds), the initial sulfur content of $0.06 \%$ and $0.03 \%$ were no obvious change. $120 \mathrm{~s}$ later, for the initial sulfur content of $0.03 \%$, the sulfur content decreased rap-

Table 1. Parameters used in model.

\begin{tabular}{|c|c|c|c|}
\hline Parameter & Meaning & Value & Units \\
\hline \multicolumn{4}{|c|}{ Desulphurization reagent characteristics } \\
\hline$\varphi_{1}$ & $\mathrm{CaO}$ mass fraction of desulfurizing agent & 40 & $\%$ \\
\hline$\varphi_{2}$ & $\mathrm{Mg}$ mass fraction of desulfurizing agent & 60 & $\%$ \\
\hline$B_{1}$ & Proportion of dissolved $\mathrm{Mg}$ & 80 & $\%$ \\
\hline$\tau_{p}$ & Residence time of powder & 25.83 & s \\
\hline$\tau_{R T}$ & Residence time of $\mathrm{Mg}$ bubble & 12.45 & s \\
\hline$\rho_{s}$ & Density of desulfurization agent & 1380 & $\mathrm{~kg} / \mathrm{m}^{3}$ \\
\hline$d_{s}$ & Reagent particle diameter & 0.001 & $\mathrm{~m}$ \\
\hline$d_{b}$ & Diameter of Mg bubble & $9.75 \times 10^{-5}$ & $\mathrm{~m}$ \\
\hline$K_{b}$ & Mass transfer coefficient of sulfur in Mg bubble surface & $2.96 \times 10^{-4}$ & $\mathrm{~m} / \mathrm{s}$ \\
\hline$k$ & Apparent reaction rate constant & $5.21 \times 10^{-5}$ & - \\
\hline$\beta$ & Powder penetration ratio & 36.39 & $\%$ \\
\hline$\eta$ & Effective coefficient of powder into the slag layer & 40 & $\%$ \\
\hline \multicolumn{4}{|c|}{ Top slag hot metal } \\
\hline$\rho_{Z}$ & Density of top slag & 3500 & $\mathrm{~kg} / \mathrm{m}^{3}$ \\
\hline$A_{\text {top }}$ & Reaction area of slag metal interface & 8.24 & $\mathrm{~m}^{2}$ \\
\hline$W_{s o}$ & Initial mass of slag & 5000 & $\mathrm{~kg}$ \\
\hline$(\% S)_{o}$ & Initial sulfur content of slag & 0.5 & $\%$ \\
\hline$K_{s}$ & Mass transfer coefficient of sulfur in slag & $4.19 \times 10^{-9}$ & $\mathrm{~m} / \mathrm{s}$ \\
\hline \multicolumn{4}{|c|}{ Hot metal hot metal } \\
\hline$\rho_{m}$ & Density of hot metal & 7138 & $\mathrm{~kg} / \mathrm{m}^{3}$ \\
\hline$W_{m}$ & Mass of hot metal & $2.1 \times 10^{5}$ & $\mathrm{~kg}$ \\
\hline$K_{m}$ & Mass transfer coefficient of sulfur in hot metal & $1.56 \times 10^{-4}$ & $\mathrm{~m} / \mathrm{s}$ \\
\hline$[\% S]_{o}$ & Initial sulfur content of hot metal & Initial condition & $\%$ \\
\hline \multicolumn{4}{|c|}{ Other parameters } \\
\hline$I_{p}$ & Injection rate & 0.2 & $\mathrm{~kg} / \mathrm{s}$ \\
\hline$Q$ & Gas flow rate & 0.0278 & $\mathrm{Nm}^{3} / \mathrm{s}$ \\
\hline$t_{\text {mix }}$ & Mixing time of molten pool & 124.3 & $\mathrm{~s}$ \\
\hline$t$ & Total injection time & Initial condition & $\mathrm{s}$ \\
\hline
\end{tabular}


Table 2. Sulfur content of samples.

\begin{tabular}{cccccccc}
\hline \multirow{2}{*}{ Number } & $\begin{array}{c}\text { Initial sulfur } \\
\text { content/\% }\end{array}$ & \multicolumn{6}{c}{ Sulfur content of desulfurization process/\% } \\
\cline { 3 - 8 } & & $300 \mathrm{~s}$ & $600 \mathrm{~s}$ & $900 \mathrm{~s}$ & $1200 \mathrm{~s}$ & $1500 \mathrm{~s}$ & $1800 \mathrm{~s}$ \\
\hline 1 & 0.0294 & 0.0247 & 0.0148 & 0.0039 & - & - & - \\
2 & 0.0301 & 0.0281 & 0.0172 & 0.0051 & - & - & - \\
3 & 0.0609 & 0.0537 & 0.0375 & 0.0271 & 0.0141 & 0.0101 & 0.0050 \\
4 & 0.0593 & 0.0514 & 0.0300 & 0.0236 & 0.0153 & 0.0092 & 0.0041 \\
\hline
\end{tabular}

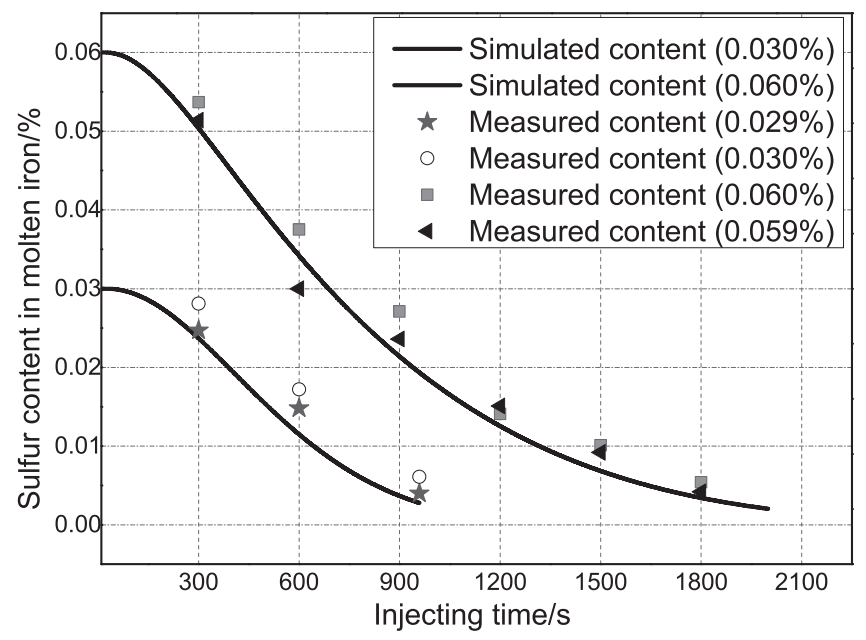

Fig. 1. Change of sulfur content in desulfurization process.

idly to below $0.005 \%$ and the desulfurization rate had not changed significantly in the process. For the initial sulfur content of $0.06 \%$, however, from 120 to $900 \mathrm{~s}$ the sulfur content decreased rapidly to below $0.015 \%$. After $900 \mathrm{~s}$, the reduction rate of sulfur content obviously decreased with time. Finally, the sulfur content decreased to below $0.005 \%$.

But there's a phenomenon that the most of the measured data is greater than the calculated data. Because the samples were taken from the upper part of ladle, and the desulfurization agent is injected from the lower part of ladle. The sulfur content of the lower part of the ladle is lower than the upper part, and the $210 \mathrm{t}$ molten iron takes 124 seconds to complete mixing. But in the calculation process, it is assumed that the molten iron is in a state of equilibrium in real time.

\subsection{Desulfurization Characteristics of High Sulfur Hot Metal}

For the high sulfur molten iron, the desulfurization efficiency was obviously changed with the injecting time. And according to the desulfurization efficiency, the desulfurization process of high sulfur molten iron is defined as three stages as shown in Fig. 2. Incubation stage, the sulfur content was no obvious change and preparing for the next stage of rapid desulfurization. Rapid desulfurization stage, from about 120 to $900 \mathrm{~s}$, the sulfur content decreased rapidly to below $0.015 \%$. Slow desulfurization stage, after 900 $\mathrm{s}$, the desulfurization efficiency decreased along with the injecting time.

According to the characteristics of high sulfur molten iron desulfurization process, in slow desulfurization stage, the utilization rate of the desulfurization agent can be improved by adjusting the injection parameters. The injection rate of

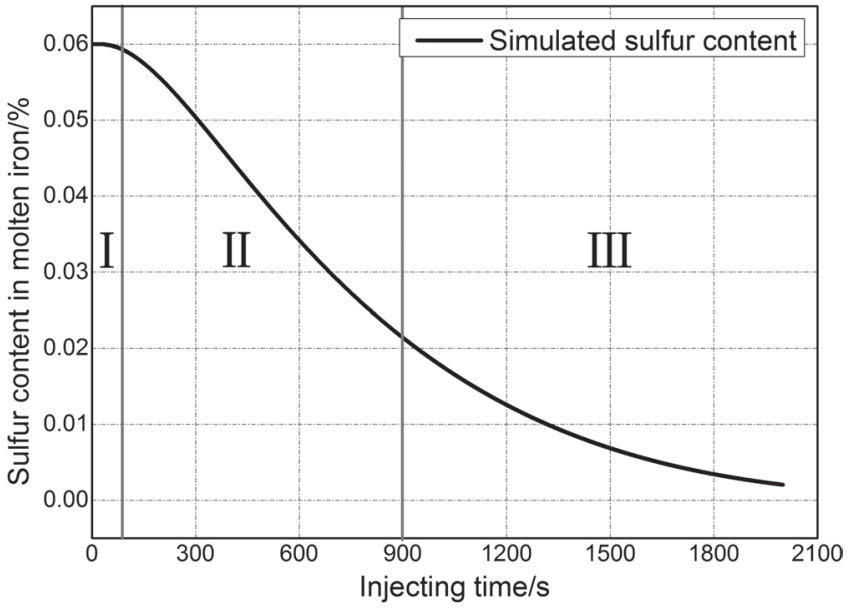

Fig. 2. Three desulfurization stages of high sulfur molten iron (I: Incubation stage; II: Rapid desulfurization stage; III: Slow desulfurization stage).

Table 3. Injection parameters of the different processes.

\begin{tabular}{|c|c|c|c|}
\hline \multirow{2}{*}{ Parameters } & \multirow{2}{*}{$\begin{array}{c}\text { Conventional } \\
\text { process }\end{array}$} & \multicolumn{2}{|c|}{$\begin{array}{l}\text { Two-stage injection } \\
\text { method }\end{array}$} \\
\hline & & $\begin{array}{c}\text { Early } \\
\text { stage (I, II) }\end{array}$ & $\begin{array}{c}\text { Later } \\
\text { stage (III) }\end{array}$ \\
\hline Injection rate of powder $/(\mathrm{kg} / \mathrm{s})$ & $0.183-0.217$ & $0.183-0.217$ & $0.133-0.150$ \\
\hline Flow rate of nitrogen $/\left(\mathrm{Nm}^{3} / \mathrm{s}\right)$ & 1.667 & 1.667 & 2.167 \\
\hline
\end{tabular}

the desulfurization agent was reduced. In order to improve the mixing of the molten pool and dynamic conditions, the flow rate of nitrogen was increased in this stage.

\subsection{Industrial Applications}

Based on the desulfurization characteristics of high sulfur hot metal, two-stage injection method was developed and applied. The injection parameters were given as follows.

The injection time of two-stage injection was the same as the conventional process. The injection time was determined by the initial sulfur content. When the initial sulfur content was greater than or equal to $0.035 \%$, the injection time was more than $1800 \mathrm{~s}$, and the lance was replaced at the half of injection time in order to improve the service life of the lance. For the two-stage injection method, at the first half of the injection time, the injection parameters were the same as the conventional process. The injection parameters were adjusted after the lance replacement. This was done to avoid the impact on the cycle because of the adjustment parameters.

Industrial tests of two-stage injection method were carried out. The initial sulfur content of tested ladles was above $0.035 \%$, and the sulfur content after the desulfurization and the steel tapping were required above $0.005 \%$ and $0.012 \%$. Tables 4 and 5 showed the industrial data of 4 ladles. The final sulfur content after the desulfurization achieved the target value below $0.005 \%$.

The changes of sulfur content during the smelting process were analyzed as shown in Fig. 3. The average sulfur content changes used the conventional process was given. It can be seen that the control of sulfur content used twostage injection method was the same with the conventional 
Table 4. Industrial test data of first stage injection.

\begin{tabular}{ccccccccc}
\hline & & & \multicolumn{5}{c}{ First stage injection } \\
\cline { 5 - 9 } NO. & Initial S/\% & Steel grade & Target S/\% & $\begin{array}{c}\text { Injection } \\
\text { time/s }\end{array}$ & $\begin{array}{c}\text { Desulphurizer } \\
\text { consumption } / \mathrm{kg}\end{array}$ & $\begin{array}{c}\text { Flow rate/ } \\
\left(\mathrm{Nm}^{3} / \mathrm{s}\right)\end{array}$ & $\begin{array}{c}\text { Injection rate of } \\
\text { powder/(kg/s) }\end{array}$ & $\begin{array}{c}\text { Pressure/ } \\
(\mathrm{Mpa})\end{array}$ \\
\hline 5102446 & 0.041 & M3A33 & 0.005 & 660 & 150.19 & 1.688 & 0.211 & 0.423 \\
5202464 & 0.041 & SPHC-P & 0.005 & 720 & 150.00 & 1.600 & 0.200 & 0.425 \\
5302495 & 0.052 & SDX51D & 0.005 & 840 & 177.90 & 1.655 & 0.200 & 0.464 \\
5202475 & 0.040 & SPHC & 0.005 & 720 & 149.00 & 1.598 & 0.208 & 0.439 \\
5302510 & 0.060 & SPHC-W1 & 0.005 & 960 & 208.30 & 1.667 & 0.213 & 0.441 \\
\hline
\end{tabular}

Table 5. Industrial test data of second stage injection.

\begin{tabular}{ccccccccc}
\hline \multirow{2}{*}{ NO. } & Initial S/\% & Steel grade & \multicolumn{7}{c}{ Second stage injection } & $\begin{array}{c}\text { Injection } \\
\text { time/s }\end{array}$ & $\begin{array}{c}\text { Desulphurizer } \\
\text { consumption/kg }\end{array}$ & $\begin{array}{c}\text { Flow rate/ } \\
\left(\mathrm{Nm}^{3} / \mathrm{s}\right)\end{array}$ & $\begin{array}{c}\text { Injection rate of } \\
\text { powder/(kg/s) }\end{array}$ & $\begin{array}{c}\text { Pressure/ } \\
(\mathrm{Mpa})\end{array}$ & Final S/\% \\
\hline 5102446 & 0.041 & M3A33 & 660 & 119.73 & 2.000 & 0.173 & 0.473 & 0.0033 \\
5202464 & 0.041 & SPHC-P & 720 & 120.12 & 1.987 & 0.168 & 0.442 & 0.0041 \\
5302495 & 0.052 & SDX51D & 840 & 149.20 & 2.006 & 0.164 & 0.448 & 0.0037 \\
5202475 & 0.040 & SPHC & 720 & 109.49 & 2.019 & 0.170 & 0.463 & 0.0041 \\
5302510 & 0.060 & SPHC-W1 & 960 & 174.31 & 2.043 & 0.174 & 0.471 & 0.0036 \\
\hline
\end{tabular}

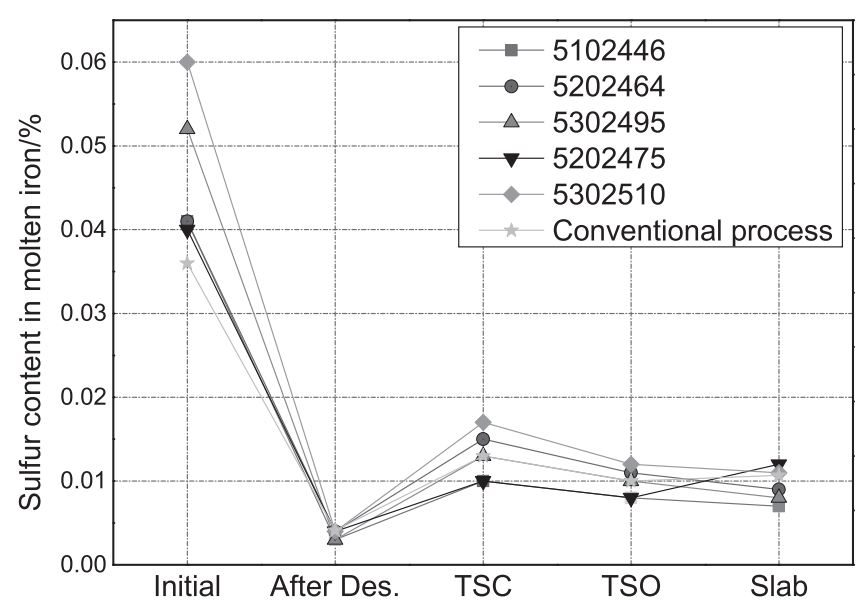

Fig. 3. Change of sulfur content (After Des.: After desulfurization, TSC: temperature sample carbon, TSO: temperature sample oxygen).

method. For the two-stage injection trials, the 5 ladles molten iron of the sulfur content more than $0.035 \%$ were selected, and they are of different steel kinds and in different cast times. The target sulfur content after Des is the same $\leq 0.005 \%$. But before TSC, according to steel kinds, the steel scraps of different sulfur content were added into the molten steels. Therefore, the sulfur content of different heats are different in TSC. With the slag-steel reaction and the oxidation reaction, the sulfur content of all heats are decreased from TSC to TSO. During the process from TSO to Slab, the sulfur content of all heats is no significant change. Finally, the sulfur content met the requirement of slabs (Requirement of slab sulfur content: M3A33 $\leq 0.010 \%$, SPHC-P/ SDX $51 D \leq 0.012 \%$, SPHC/SPHC-W $\leq 0.015 \%$ ). Finally, the sulfur content met the requirement of slabs.

For the molten iron of sulfur content $\geq 0.035 \%$, the two-stage injection method was adopted in the steel plant. Compared with the conventional process, the consumption of the desulfurizing agent is reduced by $10-20 \%$ by using the two-stage injection method.

\section{Conclusions}

A kinetic model of the injection desulphurization was established. The changes of sulfur content were analyzed. For the high sulfur molten iron, a new injection desurphurization mode was developed and applied. The following conclusions were obtained.

(1) The kinetic model of the $60 \% \mathrm{Mg}$ and $40 \% \mathrm{CaO}$ injection desulphurization was established. The result from the model was verified by sampling, and it was in accord with the sampling results.

(2) For the high sulfur molten iron, the desulfurization efficiency was obviously changed with the injecting time. The desulfurization process of high sulfur molten iron is defined as three stages, incubation stage, rapid desulfurization stage and slow desulfurization stage.

(3) For the two-stage injection method, at the first half of the injection time, the injection parameters were the same as the conventional process. In order to improve the dynamic conditions and the utilization rate of the desulfurization agent, the smaller injection rate of powder and the larger flow rate of nitrogen were used.

(4) Compared with the conventional process, the consumption of the desulfurizing agent is reduced by $10-20 \%$ by using the two-stage injection method.

\section{Nomenclature}

$$
\begin{aligned}
A_{1}, A_{\mathrm{b}} \text { : } & \text { Surface area of powder particles in } \\
& \text { contact with molten iron, bubble-melt } \\
& \text { interface }\left(\mathrm{m}^{2}\right) .
\end{aligned}
$$


$C_{[S]}, C_{(S)}, C_{S}^{e}, C_{[S]}^{b}:$ Molar volume concentration of hot metal, top slag, reaction equilibrium, bubble-melt interface $(\mathrm{mol} / \mathrm{L})$.

$J_{[S]}$ : Mass flux of sulfur $\left(\mathrm{mol} /\left(\mathrm{m}^{2} \cdot \mathrm{s}\right)\right)$.

$L_{s}$ : Sulfur partition ratio between top slag and melt.

$[\% \mathrm{Mg}]$ : Instantaneous concentration of magnesium in hot metal (\%).

$[\% S],[\% S]_{o},[\% S]_{e},[\% S]_{b}$ : Instantaneous concentration of sulfur in hot metal, initial sulfur concentration in hot metal, sulfur concentration of reaction equilibrium, sulfur concentration of bubble desulfurization equilibrium (\%).

$(\% S),(\% S)_{0}$ : Instantaneous concentration of sulfur in top slag, initial sulfur concentration in top slag (\%).

$v_{\text {total }}, v_{\mathrm{CaO}}, v_{\mathrm{Mg}}, v_{t o p}$ : Desulfurization rate of total, $\mathrm{CaO}, \mathrm{Mg}$, top slag $(\% / \mathrm{s})$.

$W_{\mathrm{s}}$ : Instantaneous mass of top slag $(\% / \mathrm{s})$.

\section{REFERENCES}

1) K. Kanbara, T. Nisugi, O. Shiraishi and T. Hatakeyama: Tetsu-toHagané, 58 (1972), 34.

2) K. Nakanishi, N. Bessyo, S. Takada, A. Ejima, M. Kuga, J. Katsuki and M. Kawana: Tetsu-to-Hagané, 64 (1978), 1528.

3) N. Kurokawa, S. Matsuo, H. Jouguchi, K. Yamada and Y. Watanabe: Sumitomo Met., 45 (1993), 52.

4) N. Kikuchi, S. Nabeshima, S. Takeuchi, T. Yamauchi, Y. Kitano and S. Ogura: Tetsu-to-Hagané, 90 (2004), 322.

5) N. Kikuchi, S. Nabeshima and Y. Kishimoto: ISIJ Int., 52 (2012), 1809.

6) S. Yamaguchi, T. Uemura, H. Nashiwa and H. Sugita: Ironmaking Steelmaking, 4 (1977), 276.

7) D. A. R. Kay, S. V. Subramanian and R. V. Kumar: Can. Inst. Min. Metall., 17 (1986), 25.

8) G. A. Irons and C. Celik: Ironmaking Steelmaking, 19 (1992), 136.

9) G. A. Irons and R. I. L. Guthrie: Ironmaking Steelmaking, 8 (1981), 114.

10) J. Diao, B. Xie and S. S. Wang: Ironmaking Steelmaking, 36 (2009), 543.

11) J. Y. Choi, D. J. Kim and H. G. Lee: ISIJ Int., 41 (2001), 216.

12) G. A. Irons: Ironmaking Steelmaking, 16 (1989), 28.

13) V. Seshadri, C. A. da Silva, I. A. da Silva and P. von Kruger: ISIJ Int., 37 (1997), 21.

14) L. H. Luo, Z. S. Zou and A. H. Liu: J. Northeast. Univ. (Nat. Sci.), 19S (1998), No. 1, 176

15) Y. F. Zhao and G. A. Irons: Ironmaking Steelmaking, 21 (1994), 309.

16) G. A. Irons and R. I. L. Guthrie: Metall. Trans. B, 12B (1981), 755.

17) N. Wang, Y. S. Zou and Z. S. Zou: J. Iron Steel Res., 12S (2000), 16.

18) N. Wang, Y. S. Zou and Z. S. Zou: J. Iron Steel Res., 12S (2000), 10 